\title{
Excitotoxicity-Associated p53 Expression in Adult Rat Retina Is Mediated by Calpain Activity but $\mathrm{Not}_{\text {by } \mathrm{Cl}^{-} \text {Influx }}$
}

\author{
Yasuhiro Hama $^{1}$, Hiroshi Katsuki ${ }^{2}$, Yasuhiko Izumi ${ }^{1}$, Toshiaki Kume ${ }^{1}$, and Akinori Akaike ${ }^{1, *}$ \\ ${ }^{1}$ Department of Pharmacology, Graduate School of Pharmaceutical Sciences, Kyoto University, \\ 46-29 Yoshida-shimoadachi-cho, Sakyo-ku, Kyoto 606-8501, Japan \\ ${ }^{2}$ Department of Chemico-Pharmacological Sciences, Graduate School of Pharmaceutical Sciences, Kumamoto University, \\ 5-1 Oe-honmachi, Kumamoto 862-0973, Japan
}

Received April 2, 2009; Accepted June 10, 2009

\begin{abstract}
We have previously demonstrated an important role of influx of $\mathrm{Cl}^{-}$rather than $\mathrm{Ca}^{2+}$ in acute excitotoxicity in adult rat retina. As p53 has been implicated in delayed apoptotic cell death, here we examined the appearance of p53 immunoreactivity in a rat eyecup preparation. Kainate induced p53 expression in a subpopulation of ganglion cells and other cells in the ganglion cell layer. Application of a calpain inhibitor, but not reduction of extracellular $\mathrm{Cl}^{-}$, markedly inhibited kainate-induced p53 expression. The results suggest that, in contrast to acute excitotoxicity, delayed excitotoxicity in retinal neurons is mediated by $\mathrm{Ca}^{2+}$-dependent processes, including calpain activation.
\end{abstract}

Keywords: apoptosis, calcium, retina

Degeneration of retinal ganglion cells (RGCs) is a prominent feature of various disorders including glaucoma, ischemia, and diabetic retinopathy. These pathological conditions may be associated with dysregulation of the glutamatergic system, leading to excitotoxic injury in the retina (1). The mechanisms of excitotoxicity in RGCs remain controversial, however, due to the lack of suitable in vitro experimental systems for evaluation of RGC death. To circumvent this problem, we have established a novel system for evaluation of RGC death using posterior eyecups prepared from adult rats (2). Using this preparation, we uncovered the dependence of acute excitotoxicity on extracellular $\mathrm{Cl}^{-}$rather than extracellular $\mathrm{Ca}^{2+}(2)$. However, the proportion of dead RGCs as assessed by propidium iodide staining was at most $15 \%$ of the total RGCs at $6 \mathrm{~h}$ after treatment with excitotoxins such as $N$-methyl-D-aspartate (NMDA) and kainate. Therefore, the present study was designed to evaluate the delayed phase of excitotoxicity that could not be detected by propidium iodide staining, because delayed apoptotic cell death may be relevant to RGC death during chronic disease states (3). For this purpose,

*Corresponding author. aakaike@pharm.kyoto-u.ac.jp Published online in J-STAGE on August 1, 2009 (in advance) doi: $10.1254 /$ jphs.09105SC we focused on $\mathrm{p} 53$ expression.

The tumor suppressor protein p53 functions as a transcription factor that upregulates the expression of the pro-apoptotic gene bax and downregulates the expression of the anti-apoptotic gene bcl-2, thereby triggering apoptosis in many cell types (4). Indeed, apoptosis induced by retinal ischemia is accompanied by increased expression of p53 mRNA (5), and mice heterozygous for the mutant $\mathrm{p} 53$ allele show resistance to RGC death induced by ischemia (6). Moreover, p53 gene polymorphism may be related to the primary open angle glaucoma (7).

Retrograde labeling of RGCs with fluoro-gold (FG; Fluorochrome, LLC, Denver, CO, USA) was performed on male 7-week-old Sprague-Dawley rats under anesthesia with pentobarbital as described (2). Four days after FG injection, rats were killed by decapitation; and the eyeballs were obtained and transferred into petri dishes containing ice-cold artificial cerebrospinal fluid (aCSF) consisting of $124 \mathrm{mM} \mathrm{NaCl}, 5 \mathrm{mM}$ $\mathrm{KCl}, 2 \mathrm{mM} \mathrm{MgSO}$, $2 \mathrm{mM} \mathrm{CaCl}_{2}, 1.25 \mathrm{mM} \mathrm{NaH}_{2} \mathrm{PO}_{4}$, $22 \mathrm{mM} \mathrm{NaHCO}$, and $10 \mathrm{mM}$ glucose. The posterior eyecups were dissected out and transferred into a sixwell plate, each well filled with $6 \mathrm{~mL}$ of aCSF maintained at $30^{\circ} \mathrm{C}$. After incubation for $90 \mathrm{~min}$, we treated the eyecups with kainate (Wako Chemicals, Osaka) by 
transferring them to a 12-well plate whose wells were filled with $3 \mathrm{~mL}$ of aCSF containing kainate at $30^{\circ} \mathrm{C}$. After $30 \mathrm{~min}$ of treatment, the eyecups were again transferred into a six-well plate, each well filled with $6 \mathrm{~mL}$ of fresh aCSF, and incubated for a further $6 \mathrm{~h}$. aCSF was saturated with $95 \% \mathrm{O}_{2} / 5 \% \mathrm{CO}_{2}$ throughout the experiments.

At termination of post-incubation, we fixed the eyecups in phosphate-buffered $4 \%$ formalin / $1 \%$ glutaraldehyde aqueous solution $(\mathrm{pH} 7.4)$ at $4^{\circ} \mathrm{C}$ overnight, and then, in phosphate-buffered $10 \%$ formalin solution ( $\mathrm{pH} 7.4)$ at $4{ }^{\circ} \mathrm{C}$ overnight. After fixation, we dehydrated the eyecups with ethanol and then immersed them in xylene. Eyecups were embedded in paraffin and cut into $5-\mu \mathrm{m}$ sections through the optic nerve of each eyecup. The sections were then subjected to immunohistochemistry with anti-p53 antibody. For antigen retrieval, specimens were incubated in $10 \mathrm{mM}$ citratebuffered solution ( $\mathrm{pH} \mathrm{6.0)}$ at $80^{\circ} \mathrm{C}$ for $30 \mathrm{~min}$. Specimens were then blocked with $1.5 \%$ goat serum in phosphate-buffered saline (PBS) at room temperature for $1 \mathrm{~h}$. Following these processes, specimens were incubated with mouse anti-p53 antibody PAb1620 (20 $\mu \mathrm{g} / \mathrm{ml}$, No. OP33; Calbiochem, Merck, Ltd., Tokyo) at $4^{\circ} \mathrm{C}$ overnight. After rinsing with PBS, specimens were incubated overnight with Alexa Fluor 568-labeled goat anti-mouse IgG (1:400; Molecular Probes, Eugene, OR, USA) at room temperature.

For each section, we randomly selected three fields of $300-\mu \mathrm{m}$ length at approximately $1 \mathrm{~mm}$ from the optic disc and acquired fluorescence images. We counted FG-labeled, p53-positive $\left(\mathrm{FG}^{+} / \mathrm{p} 53^{+}\right)$cells with the aid of Adobe Photoshop ${ }^{\circledR}$ software. For each retina, data from three sections obtained at more than $30-\mu \mathrm{m}$ distance from one another were averaged, and the number of $\mathrm{FG}^{+} / \mathrm{p} 53^{+}$cells was expressed as a ratio (\%) to that of total FG-labeled cells. In the same fields as those used for determination of $\mathrm{FG}^{+} / \mathrm{p} 53^{+}$cells (three fields of 300 $\mu \mathrm{m}$ length in each section), we also obtained the number of p53-positive cells without $\mathrm{FG}$ labeling $\left(\mathrm{FG}^{-} / \mathrm{p} 53^{+}\right.$ cells) in the ganglion cell layer (GCL) by subtracting the number of $\mathrm{FG}^{+} / \mathrm{p} 53^{+}$cells from that of p53-labeled cells.

Retinal sections obtained from eyecups maintained in aCSF without kainate for $30 \mathrm{~min}$ and incubated for a further $6 \mathrm{~h}$ in aCSF contained very few p53-positive cells (Fig. 1A). In contrast, p53-positive cells appeared when the eyecups were exposed to $1 \mathrm{mM}$ kainate for 30 min and incubated for a further $6 \mathrm{~h}$ in aCSF (Fig. 1B).
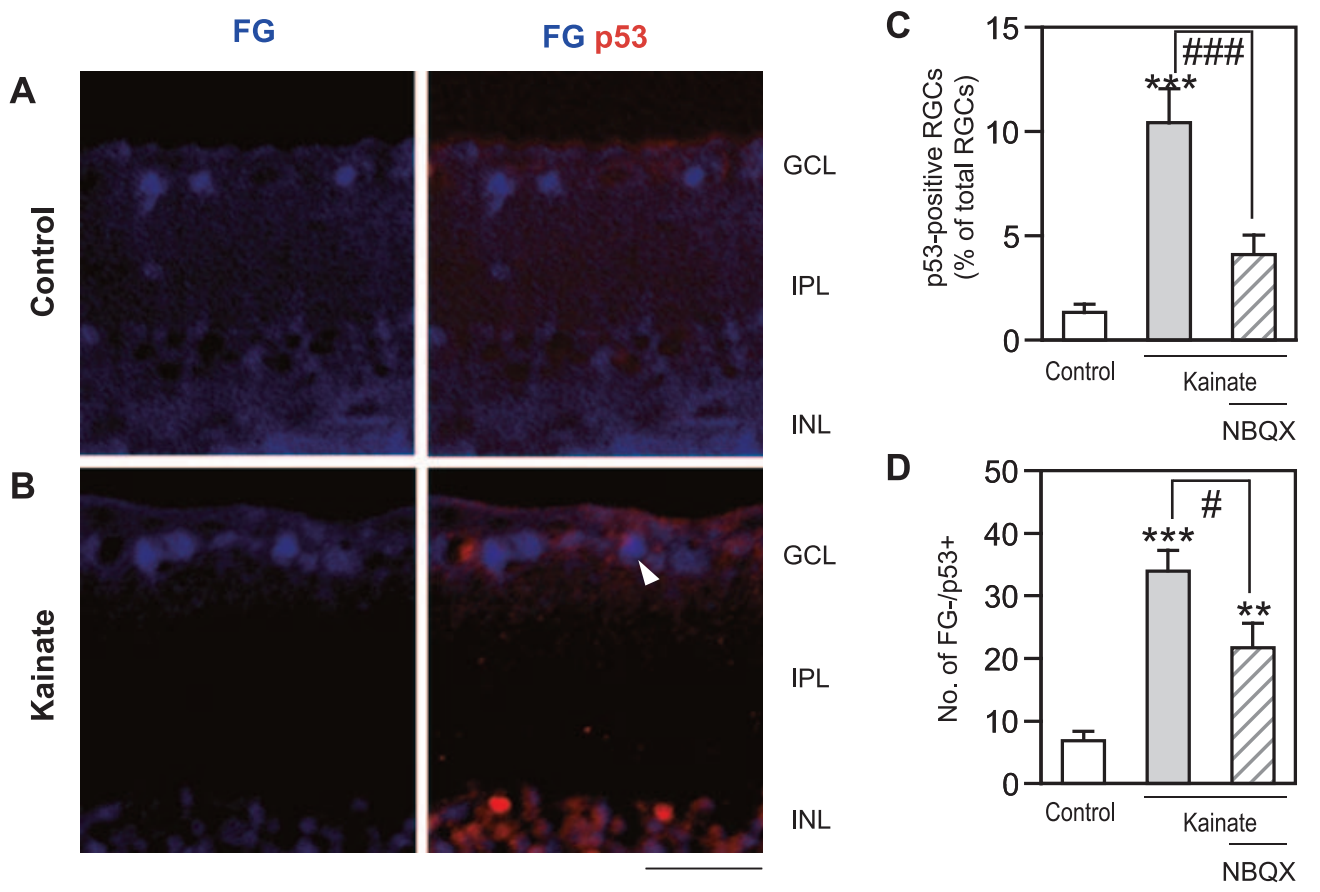

Fig. 1. Kainate-induced p53 expression in adult rat retina. Eyecups were treated with $1 \mathrm{mM}$ kainate for 30 min and then incubated in aCSF for a further $6 \mathrm{~h}$. NBQX $(30 \mu \mathrm{M})$ was applied during kainate treatment. Shown are representative photomicrographs of FG fluorescence (blue) and immunofluorescence for $\mathrm{p} 53$ (red) of retinal sections from control eyecups (A) and eyecups after kainate treatment (B). Arrowheads indicate double-labeled spots representing p53-positive RGCs. Scale bar, $30 \mu \mathrm{m}$. GCL, ganglion cell layer; IPL, inner plexiform layer; INL, inner nuclear layer. (C) The number of p53-positive $\mathrm{RGCs}\left(\mathrm{FG}^{+} / \mathrm{p} 53^{+}\right.$ cells) was expressed as a ratio (\%) to the number of total RGCs $\left(\mathrm{FG}^{+}\right.$cells). (D) The number of p53-positive cells in the GCL other than RGCs $\left(\mathrm{FG}^{-} / \mathrm{p} 53^{+}\right)$is shown. ${ }^{* *} P<0.01,{ }^{* * *} P<0.001$ vs. control. ${ }^{\sharp} P<0.05,{ }^{\# \#} P<0.001 . \mathrm{n}=7-8$ for each condition. 
Quantitative analysis revealed that $1 \mathrm{mM}$ kainate caused a significant increase in p53-positive $\mathrm{RGCs}\left(\mathrm{FG}^{+} / \mathrm{p} 53^{+}\right.$ cells) (Fig. 1C). The number of p53-positive cells other than RGCs $\left(\mathrm{FG}^{-} / \mathrm{p} 53^{+}\right.$cells) also significantly increased in response to kainate (Fig. 1D). Induction of p53 by kainate was inhibited by $30 \mu \mathrm{M} \mathrm{1,2,3,4-tetra-}$ hydro-6-nitro-2,3-dioxo-benzo $[f]$ quinoxaline-7-sulfonamide (NBQX), a non-NMDA-receptor antagonist.

As we have previously found that $\mathrm{Cl}^{-}$influx is a critical event in acute excitotoxicity in the retina (2), we examined the effect of $\mathrm{Cl}^{-}$reduction on kainate-induced p53 expression by substituting Na methanesulfonate for $\mathrm{NaCl}$ during the entire course of incubation. Interestingly, reduction of extracellular $\mathrm{Cl}^{-}$did not prevent p53 induction by $1 \mathrm{mM}$ kainate either in RGCs or in other cells in the GCL (Fig. 2: A and B). We next examined the effect of $\mathrm{Na}^{+}$substitution since acute excitotoxicity in RGCs is partially dependent on extracellular $\mathrm{Na}^{+}(2)$. Reduction of extracellular $\mathrm{Na}^{+}$, by substitution of choline $\mathrm{Cl}$ for $\mathrm{NaCl}$, significantly increased p53 expression in RGCs by itself (Fig. $2 \mathrm{C}$ ). In addition, $\mathrm{Na}^{+}$substitution did not inhibit p53 induction by kainate in cells other than RGCs (Fig. 2D). Thus, these results suggest that influx of $\mathrm{Cl}^{-}$and $\mathrm{Na}^{+}$is not important in kainateinduced $\mathrm{p} 53$ expression.

Accordingly, we set out to address the involvement of $\mathrm{Ca}^{2+}$ influx in $\mathrm{p} 53$ expression. We could not evaluate the effect of extracellular $\mathrm{Ca}^{2+}$ removal by the $\mathrm{Ca}^{2+}$ chelator EGTA because retinal tissue detachment and damage were induced in EGTA-treated eyecups in the dehydration process. Therefore, we tested the effect of MDL 28170, a calpain inhibitor. Calpains are $\mathrm{Ca}^{2+}$-activated cysteine proteases that have been reported to mediate p53 activation evoked by DNA damage (8). When MDL $28170(100 \mu \mathrm{M})$ was applied $90 \mathrm{~min}$ before kainate treatment and was present during the entire course of incubation, the drug abolished the increase in p53positive RGCs (Fig. 2E). MDL 28170 also significantly inhibited kainate-induced increase in p53-positive cells other than RGCs (Fig. 2F).

Here we revealed differences of the mechanisms between acute excitotoxicity and delayed excitotoxicity. Expression of p53, an early indicator of apoptotic cell death, was detected after $6 \mathrm{~h}$ of post-incubation following kainate treatment. DNA fragmentation may become prominent at later periods (9) that are beyond the time scale assessable in our eyecup preparation. Influx of $\mathrm{Cl}^{-}$ has been frequently implicated in excitotoxic degeneration of neuronal cells of various regions (10), and our previous study suggested that acute excitotoxic RGC death depends on $\mathrm{Cl}^{-}$influx through niflumic acidsensitive $\mathrm{Cl}^{-}$channels (2). In sharp contrast, we found here that reduction of extracellular $\mathrm{Cl}^{-}$did not prevent
A

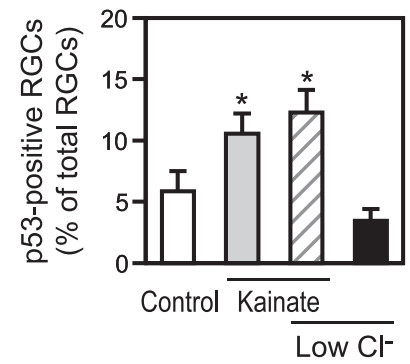

C

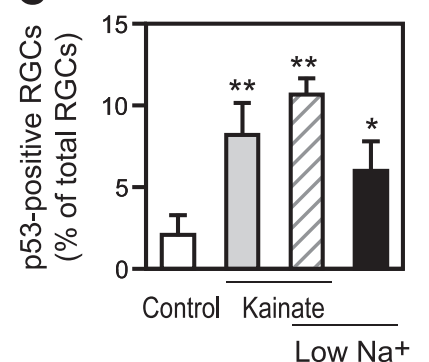

E

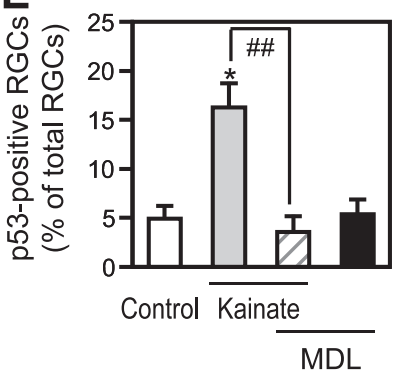

B

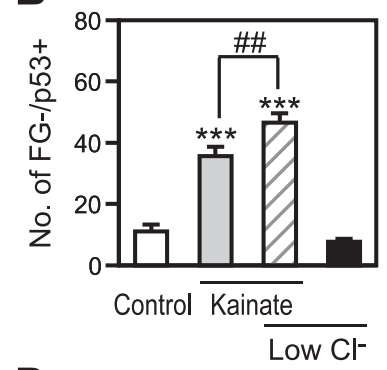

\section{D}

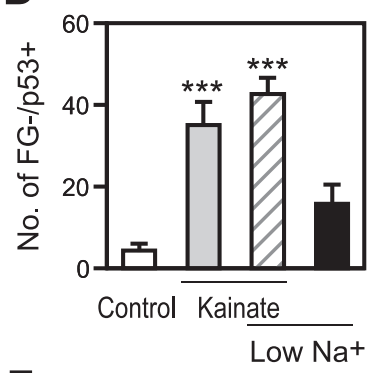

$\mathbf{F}$

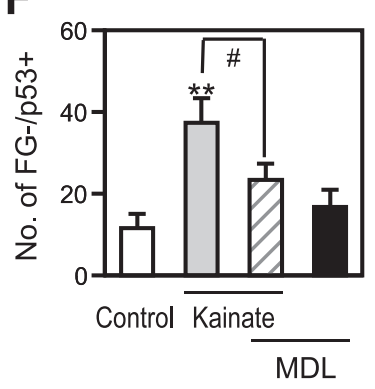

Fig. 2. Effect of ion substitution and calpain inhibition on kainateinduced p53 expression. Eyecups were treated with $1 \mathrm{mM}$ kainate for $30 \mathrm{~min}$ and then incubated in aCSF for a further $6 \mathrm{~h}$. A and B: $\mathrm{Cl}^{-}$in aCSF was reduced by substitution of $\mathrm{Na}$ methanesulfonate for $\mathrm{NaCl}$ during the entire course of incubation, and the percentage of p53positive RGCs (A) and the number of p53-positive cells other than RGCs (B) were determined. $\mathrm{n}=15-17$ for each condition. $\mathrm{C}$ and $\mathrm{D}$ : $\mathrm{Na}^{+}$in the aCSF was reduced by substitution of choline $\mathrm{Cl}$ for $\mathrm{NaCl}$ during the entire course of incubation, and the percentage of p53positive RGCs (C) and the number of p53-positive cells other than RGCs (D) were determined. $\mathrm{n}=4-6$ for each condition. $\mathrm{E}$ and $\mathrm{F}$ : MDL 28170 (MDL, $100 \mu \mathrm{M}$ ) was applied from 90 min before kainate treatment and was present during the entire course of incubation. The percentage of p53-positive RGCs (E) and the number of p53-positive cells other than RGCs (F) are shown. $\mathrm{n}=4-5$ for each condition. ${ }^{*} P<0.05,{ }^{* *} P<0.01,{ }^{* * *} P<0.001$ vs. control. ${ }^{*} P<0.05,{ }^{\# \#} P<0.01$.

kainate-induced p53 expression mediating delayed excitotoxicity in RGCs. On the other hand, MDL 28170 abolished p53 expression in RGCs induced by kainate, indicating that calpains play a crucial role in mediating delayed excitotoxicity. Because MDL 28170 also inhibits cathepsin $\mathrm{B}$, the observed effect of the compound might have resulted from cathepsin $\mathrm{B}$ inhibition. However, to our knowledge, no literature has reported the involvement of cathepsin $\mathrm{B}$ in p53 expression. $\mathrm{Ca}^{2+}$ influx following kainate application may occur via several 
pathways, including $\mathrm{Ca}^{2+}$-permeable non-NMDAreceptor channels, voltage-dependent $\mathrm{Ca}^{2+}$ channels, and $\mathrm{Na}^{+} / \mathrm{Ca}^{2+}$ exchangers. The relative contribution of these $\mathrm{Ca}^{2+}$ influx pathways to calpain activation is an important issue to be determined in future investigations.

Previous studies have pointed out potential involvement of calpains in retinal degeneration (11) and NMDA-induced excitotoxicity in adult rat retina (12). To our knowledge, however, the relationship between calpain activation and p53 expression has not yet been investigated in the retina. Sedarous et al. (8) reported that calpains mediate p53 activation after DNA damage in mouse cortical neurons and proposed that calpainmediated activation of the $\mathrm{NF} \kappa \mathrm{B}$ pathway may regulate $\mathrm{p} 53$. Calpains are known to cleave $\mathrm{I} \kappa \mathrm{B}$, a negative regulator of the $\mathrm{NF} \kappa \mathrm{B}$ pathway (13), and $\mathrm{NF} \kappa \mathrm{B}$ can activate p53 through direct transcriptional mechanisms (14). Alternatively, activation of cyclin-dependent kinase 5 through the cleavage of $\mathrm{p} 35$ to $\mathrm{p} 25$ by calpain may lead to 53 phosphorylation and activation (15).

Overall, our previous study (2) and the present one uncovered an intriguing difference in ionic dependence of acute and delayed excitotoxicity in RGCs. In vitro experimental systems for evaluation of acute RGC death with propidium iodide staining in our previous study (2) and delayed RGC death with immunohistochemistry for p53 in the present study are useful for investigating the mechanisms of excitotoxicity in the retina and searching for new drugs protecting RGCs.

\section{Acknowledgment}

This study was supported by Grants-in-Aid for Scientific Research from Japan Society for the Promotion of Science and The Ministry of Education, Culture, Sports, Science, and Technology, Japan.

\section{References}

1 Nagata T, Ueno S, Morita H, Kubota T, Toyohira Y, Tsutsui M, et al. Direct inhibition of $N$-methyl-D-aspartate (NMDA)receptor function by antiglaucomatous $\beta$-antagonists. J Pharmacol Sci. 2008;106:423-434.

2 Hama Y, Katsuki H, Suminaka C, Kume T, Akaike A. Chloridedependent acute excitotoxicity in adult rat retinal ganglion cells. Neuropharmacology. 2008;55:677-686.

3 Nickells RW. Apoptosis of retinal ganglion cells in glaucoma: an update of the molecular pathways involved in cell death. Surv Ophthalmol. 1999;43:S151-S161.

4 Culmsee C, Mattson MP. p53 in neuronal apoptosis. Biochem Biophys Res Commun. 2005;331:761-777.

5 Joo CK, Choi JS, Ko HW, Park KY, Sohn S, Chun MH, et al. Necrosis and apoptosis after retinal ischemia: involvement of NMDA-mediated excitotoxicity and p53. Invest Ophthalmol Vis Sci. 1999;40:713-720.

6 Rosenbaum DM, Rosenbaum PS, Gupta H, Singh M, Aggarwal A, Hall DH, et al. The role of $\mathrm{p} 53$ protein in the selective vulnerability of the inner retina to transient ischemia. Invest Ophthalmol Vis Sci. 1998;39:2132-2139.

7 Lin HJ, Chen WC, Tsai FJ, Tsai SW. Distributions of p53 codon 72 polymorphism in primary open angle glaucoma. $\mathrm{Br} J$ Ophthalmol. 2002;86:767-770.

8 Sedarous M, Keramaris E, O’Hare M, Melloni E, Slack RS, Elce JS, et al. Calpains mediate p53 activation and neuronal death evoked by DNA damage. J Biol Chem. 2003;278:26031-26038.

9 Perez MR, Arnér K, Håkansson A. DNA fragmentation characteristic of apoptosis and cell loss induced by kainic acid in rabbit retinas. Neurochem Int. 1997;31:251-260.

10 Inoue $\mathrm{H}$, Okada Y. Roles of volume-sensitive chloride channel in excitotoxic neuronal injury. J Neurosci. 2007;27:1445-1455.

11 Paquet-Durand F, Johnson L, Ekström P. Calpain activity in retinal degeneration. J Neurosci Res. 2007;85:693-702.

12 Chiu K, Lam TT, Li WWY, Caprioli J, Kwong JMK. Calpain and $N$-methyl-D-aspartate (NMDA)-induced excitotoxicity in rat retinas. Brain Res. 2005;1046:207-215.

13 Han Y, Weinman S, Boldogh I, Walker RK, Brasier AR. Tumor necrosis factor- $\alpha$-inducible $\mathrm{I} \kappa \mathrm{B} \alpha$ proteolysis mediated by cytosolic m-calpain. J Biol Chem. 1999;274:787-794.

$14 \mathrm{Wu} \mathrm{H}$, Lozano G. NF $\kappa$ B activation of p53. J Biol Chem. 1994;269:20067-20074.

15 Zhang J, Krishnamurthy PK, Johnson GVW. Cdk5 phosphorylates p53 and regulates its activity. J Neurochem. 2002;81:307313. 